\title{
Bio-Inspired $\mathrm{H}_{2}$ Production Catalysts
}

\author{
Dependu Dolui and Arnab Dutta* \\ Discipline of Chemistry,, India
}

*Corresponding author: Arnab Dutta, Discipline of Chemistry, India

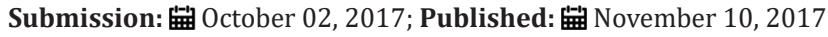

\begin{abstract}
Hydrogen is considered as one of the best possible energy vector that can effectively store the otherwise intermittent solar energy for proficient renewable energy usage. Conversion of protons to hydrogen is the heart of this scheme and this reaction requires the presence of a catalyst. Currently, the expensive Platinum (Pt)- based materials are available as one of the best catalysts but its low abundance is a barrier for its worldwide usage. Naturally occurring [ $\mathrm{FeFe}]$ - and [NiFe]-hydrogenases can also efficiently perform the $\mathrm{H}_{2}$ production reaction albeit only in a narrow chemical space $\left(25-40^{\circ} \mathrm{C}, \mathrm{pH} 4-8\right.$, mostly in absence of 02$)$. In the past decade, hydrogenase enzyme structures acts as the template for the development of numerous structural and functional model complexes. Macro cyclic cobalt complexes and nickel bis- (diphosphine) complexes containing pendant basic groups have emerged as most efficient catalysts, which are active even in heterogeneous conditions (immobilized on electro active surfaces).
\end{abstract}

Keywords: Bio-Inspired; Mimics; Catalyst; Hydrogen; Hydrogenase; Amino Acid

Abbreviations: Arg: Arginine; Bz: Benzyl; Gly: Glycine; HER: Hydrogen Evolution Reaction; kDa: KiloDalton (mass unit); OCS: Outer Coordination Sphere; $\mathrm{P}_{2} \mathrm{~N}_{2}$ : 1,5-diaza-3,7-diphosphacyclooctane; Phe: Phenyl; PY: Pyridine; SHE: Standard Hydrogen Electrode; TFA: Trifluoro acetate

\section{Introduction}

Currently, more than $85 \%$ of our energy requirement is fulfilled by the carbon based fossil fuels such as coal, oil, and natural gas [1]. The increasing human population and improving life style in modern society have affected a steep increase in global energy consumption, which in turn increased the atmospheric $\mathrm{CO}_{2}$ emission produced from the fossil fuels. Recently, the atmospheric $\mathrm{CO}_{2}$ level has surpassed 400ppm and this has impacted adversely on climate and the biosphere [2]. Thus, an alternative energy resource is sought for a solar energy is considered as one of the most promising one due to its abundance. However, the intermittent nature of the solar energy requires that it is stored properly, preferably in the form of chemical bonds, for its effective usage. Hydrogen has emerged as one of the best candidates for that role of energy carrier as it provides clean energy along with high energy density (energy density $\left.140 \mathrm{MJkg}^{-1}\right][3,4]$. The following reaction is the heart of this scheme of storing solar energy into $\mathrm{H}-\mathrm{H}$ bonds.

$$
2 \mathrm{H}^{+}+2 e^{-} \rightleftharpoons \mathrm{H}_{2}
$$

The conversion of protons to $\mathrm{H}_{2}$ requires a catalyst and currently two best available options are: (1) Platinum (Pt) based materials and (2) the natural enzyme hydrogenases. Both these systems can efficiently catalyze the reaction and can be utilized solar energy driven $\mathrm{H}_{2}$ production $[5,6]$. However, both of them have their shortcomings that have limited their usage for worldwide solar $\mathrm{H}_{2}$ production. The Pt-based materials are active in various reaction conditions, even in the harshest ones (strongly acidic, high temperature) but $\mathrm{Pt}$ is one of the most expensive metals due to its low earth abundance. On the other hand hydrogenases contain abundant $\mathrm{Ni}$ or $\mathrm{Fe}$, but they are active only in a narrow chemical space $\left(25-40{ }^{\circ} \mathrm{C}, \mathrm{pH} 4-8\right.$, mostly in absence of $\left.\mathrm{O}_{2}\right)[7,8]$. In addition to that, the active site concentration is very low for hydrogenases, where it has only one active site in protein that has size $>50 \mathrm{kDa}$ [9]. This last factor increases the operational cost for a solar energy driven hydrogen production unit that uses hydrogenases as catalyst. However, the hydrogenase enzymes provide the basic structural blue print that can be utilized to produce synthetic catalysts with analogous activity but in a broader chemical space.

Three types of hydrogenase enzyme are found in nature. They are binuclear [NiFe]-, [FeFe]- and mononuclear [Fe] hydrogenase as per the identity of the metals in the active site of the corresponding enzymes [10-12]. Thus, these enzymes contain only readily available first-row transition metals. In biology, the source of protons are generally water, thus it creates a carbon foot print free $\mathrm{H}_{2}$ cycle [3]. Hydrogen is relatively weak base but it acidity increases after binding with metal [13], thus facilitates reversible heterolytic cleavage and generation of hydrogen. It is interesting to mention that Pt-based materials follow a homolytic process for $\mathrm{H}_{2}$ production.

The overall catalytic cycle for $\mathrm{H}_{2}$ production by hydrogenases consists of the following steps:

1. Movement of protons from the bulk to the metal active site,

2. Reduction of metal bound proton to hydride (the metal is oxidized in this step), 
3. Reaction of the hydride with a neighboring proton to produce $\mathrm{H}_{2}$

4. Release of $\mathrm{H}_{2}$ to the bulk

5. Reduction of the metal center to reactivate it for the next cycle.

The hydrogenases are one of the most efficient catalysts as all the above mentioned steps are poised at thermodynamically reversible states. This is possible due to the presence of the protein scaffold around the metal center. The protein structure ensures fast movement of protons and electrons via proper positioning of basic groups and iron sulfur clusters, respectively [14]. The protein structure also minimizes the energy requirement for the structural changes of the metal active site during redox changes by inducing entatic states [15]. Thus, the surrounding protein structure plays a crucial role and it is known as the outer coordination sphere (OCS) [16].

In last few decades, bio-mimetic catalysts are mainly developed considering only the metal active site of hydrogenases and a plethora of complexes such as Cobalt dioximes, Cobalt dimine, Cobalt and Nickel diphosphines, Cobalt, Molybdenum and Ruthenium polypyridine, bimetallic dithiolato complexes and macrocyclic Cobalt complexes are produced. Although structurally some of the complexes are analogous to the enzyme active site they rarely matched the enzymatic efficiency for $\mathrm{H}_{2}$ production. Thus, it clearly indicated that the protein based OCS features are also needed to be included in the bio-inspired catalyst design. Recently, Shaw and her co-workers have developed a number of bio-inspired Ni-bis(diphosphine) complexes containing peripheral amino acids in the structure that imitates the enzyme's OCS scaffold. Interestingly, these complexes improved the catalytic efficiency compared to their parent complexes without the model OCS features. Artero et al. have demonstrated similar results when they included a synthetic Fe cluster into an apo-protein of hydrogenase to produce a fully active holoenzyme [17]. Some of these new generation bio-inspired catalysts are also immobilized on electro active surfaces and they exhibited fairly improved reactivity compared to hydrogenase enzyme in terms of reaction conditions. Current aspects for electrochemical hydrogen production by the series of these bio-mimetic catalysts are critically reviewed here.

\section{Method and Parameters for evaluation of the synthetic catalysts}

The catalytic reactivity for the synthesized complexes are evaluated via various techniques, among which electrochemical methods are the most commonly, utilized one. The two most essential parameters that determine the efficiency of a catalyst are: (i) turn over frequency (TOF) that defines the rate of the catalytic cycle and (2) over-potential, which is the excess energy required beyond the thermodynamic potential for a particular catalytic reaction (e.g. thermodynamic potential for $\mathrm{H}^{+} / \mathrm{H}_{2}$ couple is $0.0 \mathrm{~V}$ vs SHE at standard conditions). Various catalysts can be compared by those two parameters and catalysts active at a low over- potential with high TOF is considered to be better catalysts. Hydrogenase enzymes and $\mathrm{Pt}$ metal are the gold standard for $\mathrm{H}_{2}$ production catalysts and both of them exhibit TOF of $\sim 20,000 \mathrm{~s}^{-1}$ and overpotential of $<100 \mathrm{mV}$.

Both TOF and over-potential can be measured very efficiently from simple cyclic voltammetry (CV) experiments. In this procedure, at first the electrochemical response of a complex is recorded under non- catalytic conditions and the stoichiometric response in current $\left(i_{p}\right)$ is measured. Then, an analogous experiment is done under catalytic conditions and the catalytic current $\left(\mathrm{i}_{\mathrm{c}}\right)$ is recorded. Then the TOF or $\mathrm{k}_{\text {obs }}$ can be measured by using the following equation:

$$
\frac{i_{c}}{i_{p}}=\frac{n}{0.4463}\left(\frac{R T k_{o b s}}{F v}\right)^{1 / 2}
$$

Here $\mathrm{R}$ is universal gas constant, $\mathrm{F}$ is Faraday's constant, $\mathrm{T}$ is the temperature in $\mathrm{K}, \mathrm{v}$ is the scan rate in $\mathrm{Vs}^{-1}$ and $\mathrm{n}$ is the number of molecules involved in the catalytic reaction.

In certain cases (e.g. acidic aqueous solution), it is difficult to measure the stoichiometric current $\left(\mathrm{i}_{\mathrm{p}}\right)$ as it difficult to find a noncatalytic condition under similar reaction set up. In these scenarios, the TOF or $\mathrm{k}_{\mathrm{obs}}$ can be measured by using the following equation by using only the catalytic current $\left(\mathrm{i}_{\mathrm{c}}\right)$ :

$$
k_{o b s}=\frac{1}{D} \times\left(\frac{i_{c}}{n F A[c a t]}\right)^{2}
$$

Here $D$ id the diffusion coefficient of the complex under catalytic condition, F is Faraday's constant; A is the surface area of the electrode, [Cat] concentration of the catalytic complex and $n$ is the number of molecules involved in the catalytic reaction.

The over-potential is measured as the difference of the potential, where the catalytic reaction is occurring and the thermodynamic potential of the concerned catalytic reaction.

Now, the potential of the catalytic reaction can be measured at various positions such as

(i) Foot of the wave, where the catalytic response begins,

(ii) At half maxima of the current, where the catalytic response is $50 \%$ of the maximum,

(iii) At the maximum catalytic current. The calculation can be done with any of the three conditions once it is mentioned properly. During the comparison of over-potential among various catalysts the same calculation method should be used.

Coulometric technique is also used for measuring the bulk electro catalytic properties of complexes. In this chronoamperometric experiment, the current is measured at a particular potential (typically where the catalytic reaction occurs) over time. In this experiment, the overall charge (i.e. no. of electrons) passed can be measured. These experiments are generally performed in a closed system and the end of the experiment the $\mathrm{H} 2$ produced (for $\mathrm{H}^{+}$to $\mathrm{H}_{2}$ conversion catalysis) in the head space can be measured via 
gas chromatography (GC). Then the overall current efficiency (or Faradic efficiency) of the catalyst can be measured by using the following equation:

$$
\text { CurrentEfficeincy }=\frac{\text { No.ofmolesof } \mathrm{H}_{2} \text { produced }}{\text { No.ofelectronsconsumed }} \times \frac{1}{2}
$$

\section{Discussion}

Hydrogenase enzymes are an integral part of many microorganisms. Among three distinct types of hydrogenase enzyme, [FeFe]-hydrogenase are the best $\mathrm{H}_{2}$ production catalyst with turnover frequency reported $20,000 \mathrm{~s}^{-1}$ [18]. But these enzymes cannot be used directly in application system due to their bulky size and other large-scale synthesis problems along side with their narrow chemical space issues. However, some of their unique structural aspects can be incorporated into various other bioinspired mimics. For our formal discussion, we divide them into four categories. These are Clathrochelate complexes, Polypyridine complexes, Complexes with outer coordination scaffold and surface supported catalyst.

\section{Bio-inspired clathrochelate complexes}

Fisher \& Eisenberg [19] first reported water soluble Co(II) Tetraazomycrocycle $(2 \mathrm{a}, 2 \mathrm{~b})$ can produce $\mathrm{H}_{2}$ at an applied over- potential of $-1.26 \mathrm{~V}$ and $-1.36 \mathrm{~V}$ Vs SHE respectively on acetonitrile and water solvent with $80 \%$ Faradic Yield. Kellett \& Spiro [20] studied on three water-soluble Co (I) porphyrins, CoTMAP (1a), CoTPyP (1b) and CoTMPyP (1c) developing towards efficient hydrogen production catalyst. They exhibit catalytic activity at around $-0.76 \mathrm{~V}$ vs SHE in $0.1 \mathrm{M}$ TFA over $90 \%$ faradic yields on $\mathrm{Hg}$ pool electrode. Later Grätzel et al. [21] Co(Sepulchrate) ${ }^{3+}(3)$ complex shows catalytic activity at lover over-potentials $(-0.46 \mathrm{~V}$ Vs SHE) in weakly acidic medium (pH 4 phosphate buffer), but the faradic yield is much lower to 55\%. A series of Boron and Fluorine capped clathrochelated tris glyoximato cobalt complex (4a to $4 \mathrm{~d}$ ) has been synthesized, among them $4 \mathrm{a}$ and $4 \mathrm{~b}$ can reduce $\mathrm{HClO}_{4}$ to produce $\mathrm{H}_{2}$ even at very low over-potential $0.19 \mathrm{~V}$ vs SHE [22] but in case of Fluorine capped clathrochelated complexes (4c and 4d) $-\mathrm{Cl}$ group is replaced by phenyl and methyl groups its lability of metal center decrease. As a result of that, systems becomes weak efficient having high over-potential and low faradic yield [23]. When this clathrochelate cobalt oximes has been compared with various annlated glyoxymato cobalt complexes (5) in non-aqueous solvent. Annalated cobalt oximes are more active with decreasing its bulkiness around active metal centre. Annalated cobalt oximes suffer from lack of planarity so there is a room to make it even more active with by achieving planar structure (Figure 1).

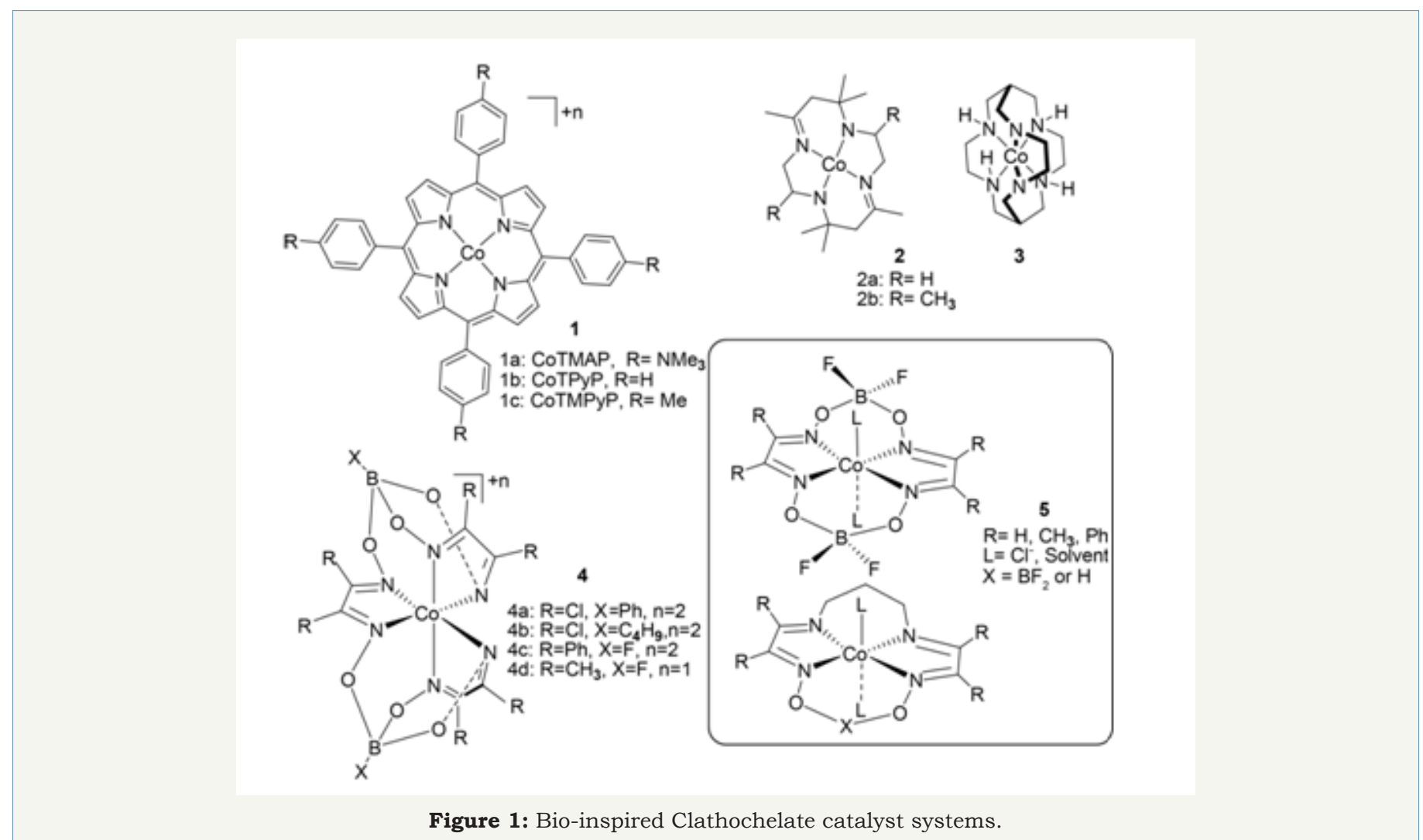

\section{Bio-inspired polypyridine catalysts}

Molybdenum and Cobalt pentapyridine complex are very efficient in neutral aqueous medium but suffer from large overpotential. Due to neutral as well as strong field ligand nature of pyridine it forms series of complex with Co (II). Complexes 6 a to $6 \mathrm{c}$ can reduce water at neutral pH. 6 a shows $99 \%$ faradic efficiency at $-1.30 \mathrm{~V}$ vs SHE. Incorporating electron withdrawing group (6b) at para position decrease the over-potential similarly over-potential increases (6c) when $-\mathrm{NMe}_{2}$ (electron donating group) group introduced. Similar type of pentapyridine Molybdenum $\left[\left(\mathrm{PY}_{5} \mathrm{Me}_{2}\right)\right.$ 
$\mathrm{MoO}^{2+}(7)$ has more efficiency than that of cobalt complexes but their catalytic activity on electrode other than mercury pool is not reported [24] as well as hydrolyzes on acidic water. A similar type of Molybdenum disulfide complex (8) is stable towards the acidic water and shows good catalytic activity [25]. Another important Pyridine based cobalt catalyst $\left[\mathrm{Co}\left(\mathrm{PY}_{4} \mathrm{OMe}\right)\right]^{2+}$ (9) which can produce hydrogen with 99\% Faradic yield in presence of TFA as a proton source on acetonitrile [26]. In 2011, Nocera et al. [27] reported macrocycle porphyrin $\mathrm{CoHPX}-\mathrm{CO}_{2} \mathrm{H}(10 \mathrm{a})$ for the effective hydrogen production catalyst and interestingly describe the effect pendant acid group adjacent to working metal center (Hangman contribution) by comparing with its Bromo (10b) variant (Figure 2).
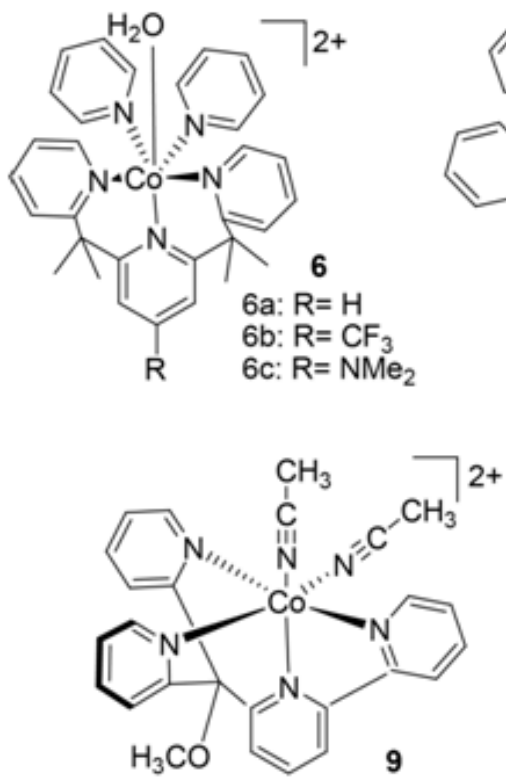

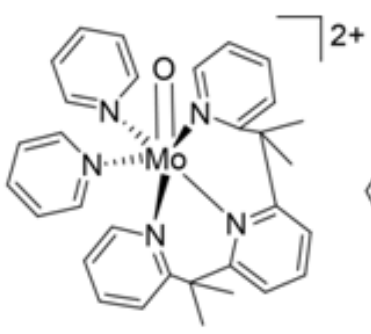

7

$\mathrm{Bu}^{\mathrm{t}}$

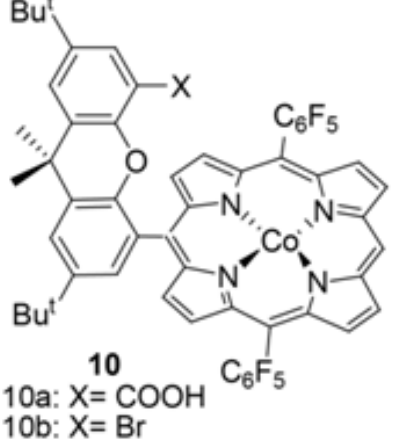

Figure 2: Various polypyridine hydrogen production catalyst.

\section{Bio-Inspired catalyst having OCS}

Mononuclear Ni(II) complex having cyclic diphosphine ligand are on-going interest for green energy hydrogen evaluation chemistry. For the sake of our discussion, we grouped these Ni(II) cyclic diphosphine into two category. One is having pendant amine in outer coordination sphere (OCS) and the other type system containing amino acid scaffold.<smiles>CCCP[N+]1P(CC)CCCP1CC</smiles>

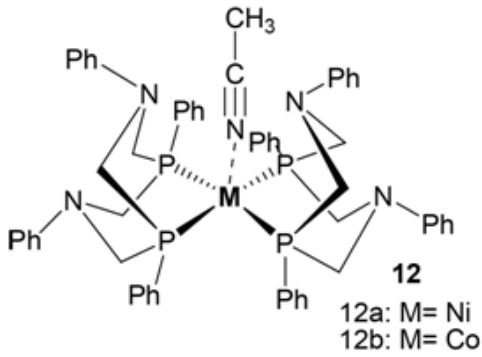

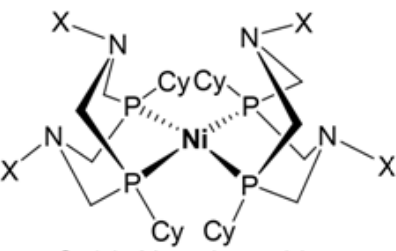

CyAA: $X=a m i n o$ acids

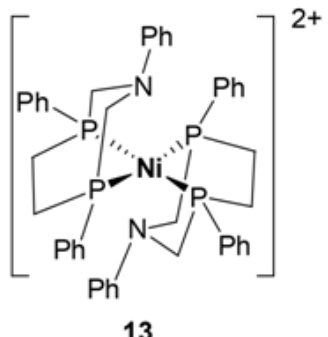

Figure 3: Various model system of Nickel(II) cyclic diphosphine catalysts. 
Nickel(II) Cyclic diphosphine containing pendant amine: DuBois et al. [28] while working with $\left[\mathrm{Ni}(\mathrm{depp})_{2}\right]^{2+}[11]$ found that it has potential to oxidize hydrogen in the presence of external amine [29]. Then they tried to introduce nitrogen backbone inside it [30]. Catalytic rate was still very low. Pendant amine has to be tuned in such a way that amine and metal center involved in the catalytic cycle jointly. Later similar type of modified catalyst has been synthesized $\left[\mathrm{Ni}\left(\mathrm{P}^{\mathrm{Ph}} 2 \mathrm{~N}^{\mathrm{Ph}}\right)\left(\mathrm{CH}_{3} \mathrm{CN}\right)\right]^{2+}(12 \mathrm{a}),\left[\mathrm{Ni}\left(\mathrm{P}_{2}^{\mathrm{cy}}{ }_{2} \mathrm{~N}^{\mathrm{bz}-\mathrm{R}}\right)\right]^{2+}$; $\left(\mathrm{R}=\mathrm{H}[31-34],-\mathrm{OMe}[35,36]\right.$ and $\left[\mathrm{Ni}\left(\mathrm{P}^{\text {cy }} 2 \mathrm{~N}\left({ }^{3-p r i d a z y l)}\right){ }_{2}\right)\right]^{2+}[37,38]$ $\left(\mathrm{P}_{2} \mathrm{~N}_{2}\right.$ : 1,5-diaza-3,7-diphosphacyclooctane). Complex 12a shows efficient catalytic activity for hydrogen production, but others are mainly active for $\mathrm{H}_{2}$ oxidation. [ $\left.\mathrm{Co}\left(\mathrm{P}^{\mathrm{Ph}}{ }_{2} \mathrm{~N}_{2}^{\mathrm{Ph}}\right)\left(\mathrm{CH}_{3} \mathrm{CN}\right)\right]^{2+}(12 \mathrm{~b})$ shows activity at relatively high over-potential and partially dissociate into $\left(\mathrm{P}_{2}^{\mathrm{Ph}} \mathrm{N}_{2}^{\mathrm{Ph}}\right)$ during electro catalysis [32]. Also, series of other active $\left[\mathrm{Ni}\left(\mathrm{P}_{2}^{\mathrm{Ph}}{ }_{2} \mathrm{NX}_{2}\right)\right]^{2+}\left(\mathrm{X}=\mathrm{OMe}, \mathrm{CF}_{3}, \mathrm{Br}, \mathrm{H}, \mathrm{Me}, \mathrm{CH}_{2} \mathrm{P}(\mathrm{O})(\mathrm{OEt})_{2}\right)$ systems have been synthesized [33]. Tuning the proton relay position and chance of enhancing endo isomer formation $\left[\mathrm{Ni}\left(\mathrm{P}^{\mathrm{Ph}}{ }_{2} \mathrm{NPh}_{2}\right]^{2+}(13)\right.$ shows extremely high turnover frequency, almost $1,00,000 \mathrm{~S}^{-1}$ in dry acetonitrile [34] (Figure 3).

Nickel(II) Cyclic diphosphine containing amino acids: Successful attempts were made to incorporate carboxylic ester function into the neighbors of the active site that will continuously relay proton source. $\left[\mathrm{Ni}\left(\mathrm{P}_{2}^{\mathrm{cy}}{ }_{2} \mathrm{~N}_{2}^{\mathrm{bz}-\mathrm{R}}\right)\right]^{2+}, \mathrm{R}=-\mathrm{COOMe},-\mathrm{CO}$-alaninemethyl ester, -CO- phenyl alanine-methyl ester [35] shows less activity than it parent $\mathrm{R}=\mathrm{H}$. The inclusion of single amino acid in the pendant amine groups increase the reactivity and resolves the problem of durability and water solubility [39]. First generation $\left[\mathrm{Ni}\left(\mathrm{P}_{2}^{\text {cy }}{ }_{2} \mathrm{~N}^{\text {amino acid }}{ }_{2}\right)\right]^{\mathrm{n+}}$ (CyAA) catalyst can catalyze fully reversible $\mathrm{H}_{2}$ production/oxidation at a high rate. Additional Guanidinium structural feature makes CyArg more facile than CyGly. The slower turnover frequency of CyArg-methyl ester from CyArg and of CyTyr from CyTym (Tym= Tyramine) reveals the importance of carboxylic group as a coupler for proton and electron transfer $[37,40]$. In water solvent, the activity of this CyAA catalyst order is CyArg $>$ CyGly $>$ CyAsp $>$ CyLys $[41,42]$. In methanol solvent, order of efficiency becomes CyAsp $\simeq$ CyPhe $>$ CyArg $\simeq$ CyLys. Temperature also effects in their activities on fuel cells [43]. Attempts were also made to incorporate peptide or diamino acid backbone into the bio-mimic of Nickel superoxide dismutase enzyme $[39,40]$ and to the synthetic mimic of [FeFe] hydrogenase enzyme [41] to get a metallic cluster. Among synthetic intermediate of diamino acid catalyst during hydrogen production proportions of endo protons observed $100 \%$ for $(\mathrm{H})_{2} \mathrm{Cy}$ (AspPhe); $70 \%$ for $(\mathrm{H})_{2} \mathrm{Cy}$ (PheGly) and $30 \%$ for $(\mathrm{H})_{2} \mathrm{Cy}$ (GlyPhe). Movement of protons facilitated from endo positioned proton proved from experimental observation of TOF: Cy(AspPhe)>Cy(PheGly)>Cy(GlyPhe) [43].

\section{Surface supported catalyst}

$\left[\mathrm{Ni}\left(\mathrm{P}_{2}^{\mathrm{cy}} \mathrm{N}_{2}{ }_{2}\right)\right]^{2+}$ immobilization was the first successful attempt to direct comparison between $[\mathrm{NiFe}]$ and Bio-inspired synthetic enzyme on the working electrode. Its TOF increase with decreasing $\mathrm{pH}$ and need $146 \mathrm{mV}$ more over-potential than that of hydrogenase modified Pt electrode at $\mathrm{pH}$ 5. At low $\mathrm{pH}$ and high temperature imobolized Ni complex operates at a similar potential at room temperature and neutral $\mathrm{pH}$ condition of hydrogenase enzyme [36]. Active [ $\left.\mathrm{Ni}\left(\mathrm{P}_{2}^{\mathrm{cy}} \mathrm{N}^{\mathrm{Arg}}{ }_{2}\right)\right]$ catalyst immobilized on the 2-amino-6napthoic acid modified single wall carbon nanotubes (CWNTs). Immobilization results in the activity on a broader range of $\mathrm{pH}$ and make it most performing hydrogen-oxidizing electrode till reported [44,45]. Recently Dey et al. [46] have synthesized a [FeFe] $\mathrm{H}_{2}$-ase mimics having azadithiolato (ATD) bridge and a terminal alkyne. Using "click reaction" this azide covalently attached to the edge plane graphite surface and reduced graphine oxide surfaces. Modified catalyst shows HER reactive for prolong hours from acidic water.

\section{Conclusion}

Side chain interaction is crucial for reversibility. Carboxylic groups give two important advances; structural stability by hindering isomerization and proton relays. The high reactivity of natural enzyme will be well understood by adding amino acids or peptide chains via "top-down" method. Still, these are in early stages of development to achieve actual OCS as that of the natural enzyme. Structural features, temperature, solvent, active site, OCS, the chain lengths of OCS, proton source all collectively make a system whether active or not. There is an enormous scope in future for tuning OCS in such a way that it will give cost-effective, highly durable efficient material for alternate energy sources.

\section{References}

1. Olah GA, Goeppert A, Prakash GS (2008) Chemical recycling of carbon dioxide to methanol and dimethyl ether: from greenhouse gas to renewable, environmentally carbon neutral fuels and synthetic hydrocarbons. J Org Chem 74(2): 487-498.

2. Monastersky R (2013) Global carbon dioxide levels near worrisome milestone. Nature 497 (7447): 13.

3. Wang M, Chen L, Sun L (2012) Recent progress in electrochemical hydrogen production with earth- abundant metal complexes as catalysts. Energy Environ Sci 5(5): 6763-6778.

4. Zhu X, Zhang T, Sun Z, Chen H, Guan J, et al. (2017) Black Phosphorus Revisited: A Missing Metal-Free Elemental Photocatalyst for Visible Light Hydrogen Evolution Ad Mater 29(17).

5. Esswein AJ, Nocera DG (2007) Hydrogen production by molecular photocatalysis. Chem Rev 107(10): 4022-4047.

6. Du P, Schneider J, Jarosz P, Zhang J, Brennessel WW, et al. (2007) Photoinduced electron transfer in platinum (II) terpyridyl acetylide chromophores: reductive and oxidative quenching and hydrogen production. J Phy Chem B 111(24): 6887-6894.

7. Ghirardi ML, Zhang L, Lee JW, Flynn T, Seibert M, et al. (2000) Microalgae: a green source of renewable $\mathrm{H}_{2}$. Trends Biotechnol 18(12): 506-511.

8. Stripp ST, Goldet G, Brandmayr C, Sanganas O, Vincent KA, et al. (2009) How oxygen attacks [FeFe] hydrogenases from photosynthetic organisms. Proc Natl Acad Sci USA 106(41): 17331-17336.

9. Nicolet Y, Piras C, Legrand P, Hatchikian CE, Fontecilla-Camps JC (1999) Desulfovibrio desulfuricans iron hydrogenase: the structure shows unusual coordination to an active site Fe binuclear center. Structure $7(1): 13-23$.

10. Tard C, Pickett CJ (2009) Structural and functional analogues of the active sites of the $[\mathrm{Fe}]-[\mathrm{NiFe}]-$, and [FeFe]-hydrogenases. Chem Rev 109(6): 2245-2274. 
11. Shima S, Pilak O, Vogt S, Schick M, Stagni MS, et al. (2008) The crysta structure of [Fe]-hydrogenase reveals the geometry of the active site. Science 321(5888): 572-575.

12. Lubitz W, Ogata H, Rü diger O, Reijerse E (2014) Hydrogenases. Chem Rev 114(8): 4081-4148.

13. Lubitz W, Tumas W (2007) Hydrogen: an overview. Chem Rev 107(10): 3900-3903.

14. Shaw WJ, Helm ML, DuBois DL (2013) A modular, energy-based approach to the development of nickel containing molecular electrocatalysts for hydrogen production and oxidation. Biochim Biophys Acta 1827(8): 1123-1139.

15. Ginovska PB, Ho MH, Linehan JC, Cheng Y, Dupuis M, et al. (2014) Molecular dynamics study of the proposed proton transport pathways in [FeFe]-hydrogenase. Biochim Biophys Acta (BBA)- Bioenergetics 1837(1): 131-138.

16. Ginovska PB, Dutta A, Reback ML, Linehan JC, Shaw WJ (2014) Beyond the active site: the impact of the outer coordination sphere on electrocatalysts for hydrogen production and oxidation. Acc Chem Res 47(8): 2621-2630.

17. Berggren G, Adamska A, Lambertz C, Simmons TR, Esselborn J, et al (2013) Biomimetic assembly and activation of [FeFe]-hydrogenases. Nature 499(7456): 66-69.

18. Madden C, Vaughn MD, Díez-Pérez I, Brown KA, King PW, et al. (2011) Catalytic turnover of [FeFe]- hydrogenase based on single-molecule imaging. J Am Chem Soc 134(3): 1577-1582.

19. Fisher BJ, Eisenberg R (1980) Electrocatalytic reduction of carbon dioxide by using macrocycles of nickel and cobalt. J Am Chem Soc 102(24): 7361-7363.

20. Kellett RM, Spiro TG (1985) Cobalt (I) porphyrin catalysts of hydrogen production from water. Inorg Chem 24(15): 2373-2377.

21. V Houlding, T Geiger, U Kölle, M Grätzel (1982) Electrochemical and photochemical investigations of two novel electron relays for hydrogen generation from water. J Chem Soc Chem Commun 152: 681-683.

22. Voloshin YZ, Dolganov AV, Varzatskii OA, Bubnov YN (2011) Efficient electrocatalytic hydrogen production from $\mathrm{H}+$ ions using specially designed boron-capped cobalt clathrochelates. Chem Commun 47(27): 7737-7739.

23. Pantani $\mathrm{O}$, Naskar $\mathrm{S}$, Guillot R, Millet $\mathrm{P}$, Anxolabéhère ME, et al. (2008) Cobalt Clathrochelate Complexes as Hydrogen-Producing Catalysts. Angew Chem Int Ed 47(51): 9948- 9950.

24. Karunadasa HI, Chang CJ, Long JR (2010) A molecular molybdenumoxo catalyst for generating hydrogen from water. Nature 464 (7293): 1329-1333.

25. Karunadasa HI, Montalvo E, Sun Y, Majda M, Long JR, et al. (2012) A molecular MoS2 edge site mimic for catalytic hydrogen generation. Science 335(6069): 698-702.

26. Bigi JP, Hanna TE, Harman WH, Chang A, Chang CJ (2010) Electrocatalytic reduction of protons to hydrogen by a water-compatible cobalt polypyridyl platform. Chem Commun 46(6): 958-960.

27. Lee CH, Dogutan DK, Nocera DG (2011) Hydrogen generation by hangman metalloporphyrins. J Am Chem Soc 133(23): 8775-8777.

28. Curtis CJ, Miedaner A, Ellis WW, DuBois DL (2002) Measurement of the hydride donor abilities of [HM (diphosphine) 2]+ complexes $(\mathrm{M}=\mathrm{Ni}$, $\mathrm{Pt}$ ) by heterolytic activation of hydrogen. J Amer Chem Soc 124(9): 1918-1925.

29. Berning DE, Miedaner A, Curtis CJ, Noll BC, Rakowski MCB, et al (2001) Free-energy relationships between the proton and hydride donor abilities of [HNi (diphosphine) 2]+ complexes and the half-wave potentials of their conjugate bases. Organometallics 20(9): 1832-1839.
30. Curtis CJ, Miedaner A, Ciancanelli R, Ellis WW, Noll BC, et al. (2003) [Ni (Et2PCH2NMeCH2PEt2) 2] 2+ as a functional model for hydrogenases. Inorg Chem 42(1): 216-227.

31. Wilson AD, Newell RH, McNevin MJ, Muckerman JT, Rakowski DB, et al. (2006) Hydrogen oxidation and production using nickel-based molecular catalysts with positioned proton relays. J Amer Chem Soc 128(1): 358-366

32. Jacobsen GM, Yang JY, Twamley B, Wilson AD, Bullock RM, et al. (2008) Hydrogen production using cobalt-based molecular catalysts containing a proton relay in the second coordination sphere. Energy Environ Sci 1(1): 167-174.

33. Kilgore UJ, Roberts JA, Pool DH, Appel AM, Stewart MP, et al. (2011) [Ni (PPh2NC6H4X2) 2] 2+ complexes as electrocatalysts for $\mathrm{H} 2$ production: effect of substituents, acids, and water on catalytic rates. J Amer Chem Soc 133(15): 5861-5872.

34. Helm ML, Stewart MP, Bullock RM, DuBois MR, DuBois DL (2011) A synthetic nickel electrocatalyst with a turnover frequency above 100,000 s-1 for H2 production. Science 333(6044): 863-866.

35. Lense S, Ho MH, Chen S, Jain A, Raugei S et al. (2012) Incorporating amino acid esters into catalysts for hydrogen oxidation: steric and electronic effects and the role of water as a base. Organometallics 31(19): 6719-6731.

36. Rodriguez-Maciá P, Dutta A, Lubitz W, Shaw WJ, Rüdiger O (2015) Direct Comparison of the Performance of a Bio-inspired Synthetic Nickel Catalyst and a [NiFe]-Hydrogenase, Both Covalently Attached to Electrodes. Angew Chem Int Ed 54(42): 12303-12307.

37. Lense S, Dutta A, Roberts JA, Shaw WJ (2014) A proton channel allows a hydrogen oxidation catalyst to operate at a moderate overpotential with water acting as a base. Chem Commun 50(7): 792-795.

38. Dutta A, Lense S, Roberts JA, Helm ML, Shaw WJ (2015) The Role of Solvent and the Outer Coordination Sphere on H2 Oxidation Using [Ni (PCy2NPyz2) 2] 2+. Eur J Inorg Chem 2015(31): 5218-5225.

39. Neupane KP, Gearty K, Francis A, Shearer I (2007) Probing variable axial ligation in nickel superoxide dismutase utilizing metallopeptide-based models: insight into the superoxide disproportionation mechanism. J Amer Chem Soc 129(47): 14605-14618.

40. Dutta A, Hamilton GA, Hartnett HE, Jones AK (2012) Construction of heterometallic clusters in a small peptide scaffold as [NiFe]-hydrogenase models: development of a synthetic methodology. Inorg Chem 51(18): 9580-9588.

41. Jones AK, Lichtenstein BR, Dutta A, Gordon G, Dutton PL (2007) Synthetic hydrogenases: incorporation of an iron carbonyl thiolate into a designed peptide. J Amer Chem Soc 129(48): 14844-14845.

42. Dutta A, DuBois DL, Roberts JA, Shaw WJ (2014) Amino acid modified $\mathrm{Ni}$ catalyst exhibits reversible $\mathrm{H} 2$ oxidation/production over a broad $\mathrm{pH}$ range at elevated temperatures. Proc Natl Acad Sci USA 111(46): 16286-16291.

43. Boralugodage NP, Arachchige RJ, Dutta A, Buchko GW, Shaw WJ (2017) Evaluating the role of acidic, basic, and polar amino acids and dipeptides on a molecular electrocatalyst for $\mathrm{H} 2$ oxidation. Catal Sci Technol 7(5): 1108-1121.

44. Gentil S, Lalaoui N, Dutta A, Nedellec Y, Cosnier S et al. (2017) CarbonNanotube-Supported Bio- Inspired Nickel Catalyst and Its Integration in Hybrid Hydrogen/Air Fuel Cells. Angew Chem Int Ed 56(7): 1845-1849.

45. Priyadarshani N, Dutta A, Ginovska B, Buchko GW, O’Hagan M et al. (2016) Achieving reversible $\mathrm{H} 2 / \mathrm{H}+$ interconversion at room temperature with enzyme-inspired molecular complexes: A mechanistic study. ACS Catal 6(9): 6037-6049.

46. Ahmed ME, Dey S, Mondal B, Dey A (2017) H2 evolution catalyzed by a FeFe-hydrogenase synthetic model covalently attached to graphite surfaces. Chem Commun 53(58): 8188-8191. 